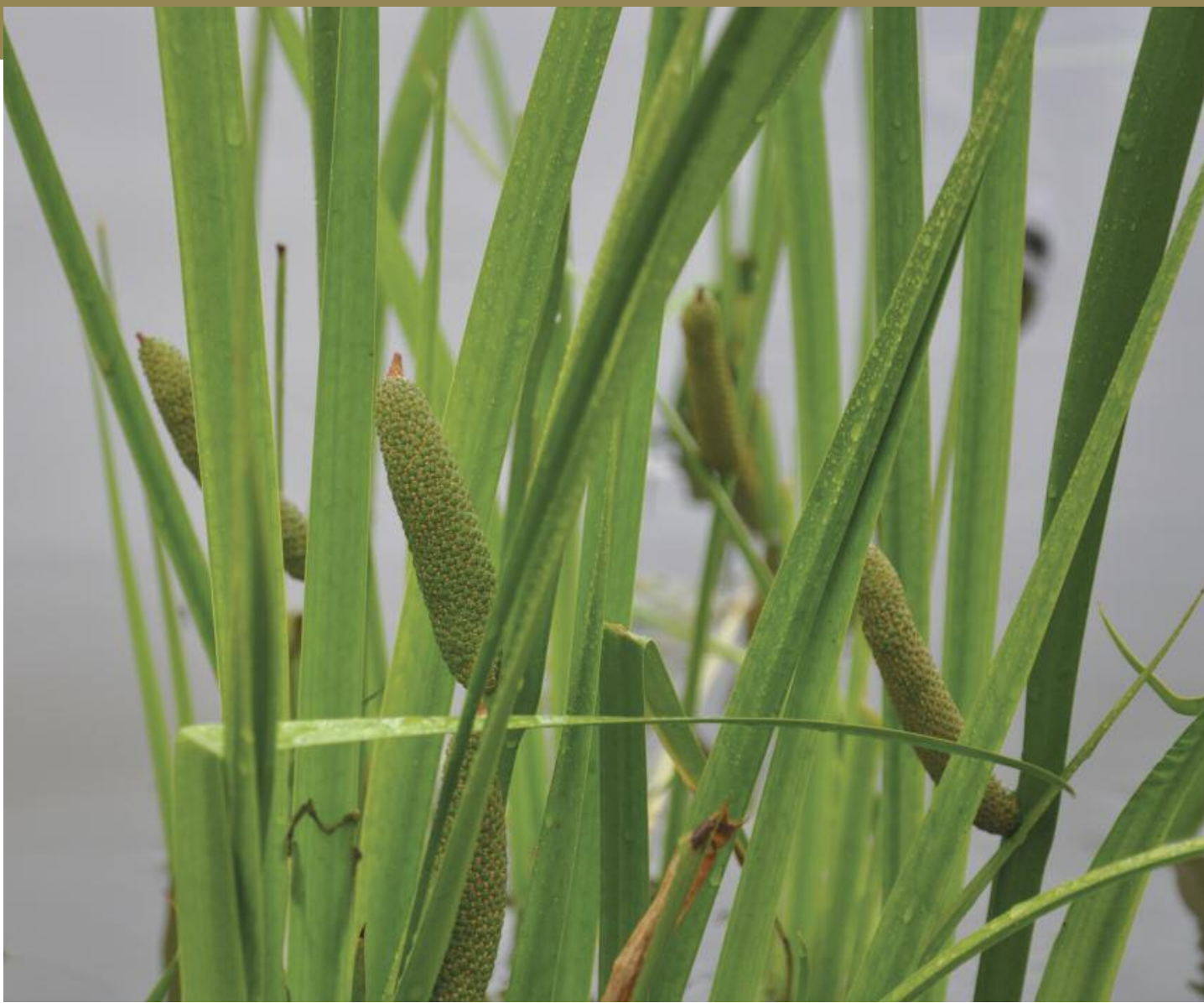

Spadix on a ratroot plant $1 \mathrm{y}$ after outplanting.

\title{
Propagation protocol for ratroot (Acorus americanus)
}

Ann Smreciu, Stephanie Wood, Kimberly Gould, and Barry Wood

\section{ABSTRACT}

Ratroot, or Acorus americanus (Raf.) Raf. (Acoraceae), can be propagated from seed harvested from natural sites in northeastern Alberta. Light is required for germination, and germination is most successful at warm temperatures $\left(15 / 25^{\circ} \mathrm{C}\right)$. Seedlings can be quickly ( $<4 \mathrm{mo}$ ) and easily produced under greenhouse conditions. Additionally, elongating rhizomes (either from wild harvest or greenhouse production) can be successfully divided to multiply plants and to produce larger stock. Ratroot is found in many wetlands throughout northern Alberta and is an important medicinal plant for Aboriginal peoples.
Smreciu A, Wood S, Gould K, Wood B. 2014. Propagation protocol for ratroot (Acorus americanus). Native Plants Journal 15(3):219-221.

\section{KEY WORDS}

rhizome division, germination, Aboriginal peoples, container seedlings, aquatic plant, oil sands, Acoraceae

\section{NOMENCLATURE ITIS (2014)}

Photos courtesy of Wild Rose Consulting Inc

\section{CONVERSIONS}

$\mathrm{m} \times 3.3=\mathrm{ft}$

$\mathrm{cm} \times 0.4=$ in

$\left({ }^{\circ} \mathrm{C} \times 1.8\right)+32={ }^{\circ} \mathrm{F}$

$\mathrm{ml} \times 0.6=\mathrm{cu}$ in 
$\mathrm{R}$ atroot (Acorus americanus (Raf.) Raf. [Acoraceae]), also known as sweet flag or calamus, is an herbaceous, boreal wetland species that grows to about $1.5 \mathrm{~m}$ tall. It has bright green, lanceolate, basal leaves that grow from a rattail-like rhizome but can most easily be recognized by its sweet aromatic scent and its yellowish-brown spadix that projects from the flowering stalk approximately three-quarters of the way up the stem. It naturally reproduces from seeds and rhizomes, the latter sprouting off shoots and roots at each node. Ratroot is widely distributed in North America; across Canada and south to Texas and Florida as an emergent species in marshes, shallow ponds and lakes, stream edges, and ephemeral streams and swamps (Moss 1983). It is often found as a component of floating cattail (Typha latifolia L. [Typhaceae]) mats. In northern Alberta, this plant flowers from July to early August, and seeds ripen in mid to late September. Flowers arise in a spadix borne laterally on a leaf-like flowering stalk. The spadix consists of many small, yellow-brown flowers that develop into small hard capsules each containing several (3-6) seeds. Seeds are cream-colored, lentiform, and approximately $3 \mathrm{~mm}$ in length.

Wetlands are, and will be, significant features in reclaimed landscapes in the oil sands region of northeastern Alberta, Canada. Interest in growing and establishing ratroot in constructed wetlands is heightened as it is a culturally significant plant to local Aboriginal peoples (Motley 1994; Marles and others 2000). It is one of the most widely known and utilized of all their medicinal and food plants. Ratroot is also ecologically significant. It provides food and cover for waterfowl, and rhizomes provide a food source for small mammals such as muskrat (Bush 2002). Ratroot has been recommended for use in revegetation of disturbed and created wetlands; however, little information is available regarding propagation of this species. Although natural ingress by select aquatic species has been observed, ratroot has not readily colonized any constructed wetlands or compensation lakes on reclaimed oil extraction sites in this area.

\section{SEEDLING PROPAGATION}

\section{Seed Harvest}

We harvested seeds from natural sites within the Municipal District of Wood Buffalo (northeastern Alberta), in early to mid-September, by cutting or plucking the entire seed head (spadix) from the stalk and placing it into a breathable bag (for example, Tyvek). Bagged seed heads are spread out in a warm (20 to $25^{\circ} \mathrm{C}$ ) dry location. After they have dried, individual capsules come away from the stalk with ease. Each head contains between 1700 and 2700 seeds (492-652 capsules/head with an average of 3-4 seeds/capsule).

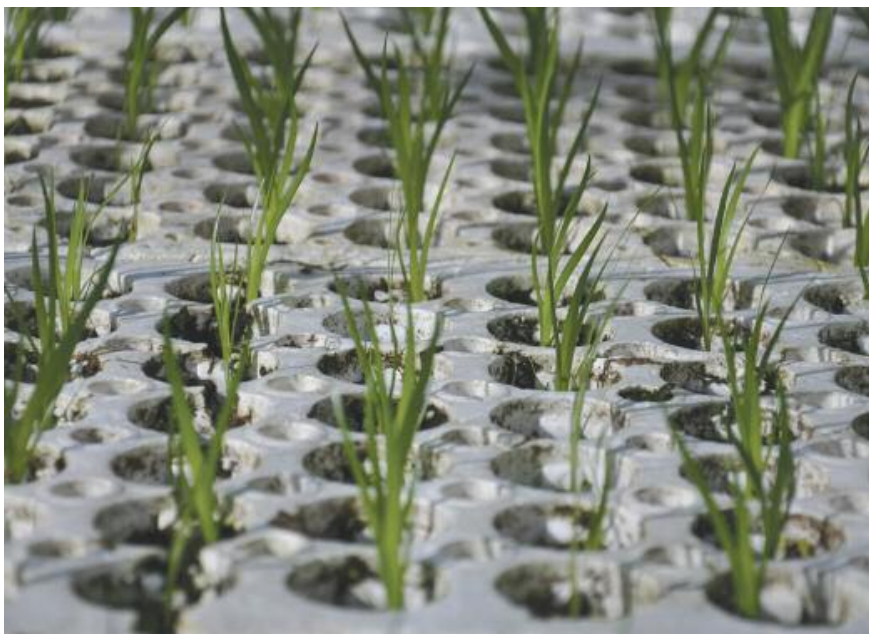

Figure 1. Ratroot seedlings $3 \mathrm{wk}$ after germination in Styroblock 620A containers.

\section{Seed Treatments}

We extract seeds using a combination of sieves (Standard Testing Sieves, Fisher Scientific USA). We break apart capsules by scrubbing them on a No. 8 sieve ( $2.36 \mathrm{~mm}$ opening), catch seeds in a No. 18 sieve ( $0.1 \mathrm{~cm}$ opening), and finally we winnow the material. Seeds are stratified on moistened batting for $4 \mathrm{wk}$ at 2 to $4{ }^{\circ} \mathrm{C}$ in a refrigerator.

\section{Seedling Culture}

In early spring (mid-February to early March), surface-sow seeds into trays $(28 \mathrm{~cm}$ wide $\times 54 \mathrm{~cm}$ long $\times 6.7 \mathrm{~cm}$ deep) filled with $100 \%$ blonde Sphagnum peat moss adjusted to $\mathrm{pH} 5.5$ to 7 with lime. We incubate the seeded trays in the greenhouse at temperatures of $25 / 15^{\circ} \mathrm{C}$. Seedlings begin to emerge in approximately $10 \mathrm{~d}$ but can continue for a period of up to a month. Emergent seedlings are pricked-out when they reach about 3 to $4 \mathrm{~cm}$ and are transplanted into Styroblock containers $620 \mathrm{~A}$ (5.9 $\mathrm{cm}$ diameter with $1.8 \mathrm{~cm}$ diameter drain hole, $20 \mathrm{~cm}$ deep, and a volume of $440 \mathrm{ml}$; Beaver Plastics, Acheson, Alberta) (Figure 1) filled with the same medium as used in the seeding trays. Irrigate seedlings daily and keep moist (based on visual inspection). We fertilize plants every $2 \mathrm{wk}$ with a complete fertilizer to provide $117 \mathrm{ppm}$ nitrogen $(\mathrm{N}), 77 \mathrm{ppm}$ phosphorus $(\mathrm{P})$, and $165 \mathrm{ppm}$ potassium $(\mathrm{K})$. Plants are fertigated until excess solution flowed from the plug. Seedlings can be outplanted in late spring to early summer ( $<4$ mo after emergence), although better establishment results from larger seedlings, making overwinter storage beneficial. Small seedlings can be grown-on in the greenhouse into late fall at which time the shoots are cut back to a few $\mathrm{cm}$, the blocks wrapped in plastic, and stored frozen $\left(-3\right.$ to $\left.-4{ }^{\circ} \mathrm{C}\right)$ over winter. Place the Styroblock containers back into the greenhouse in February or March, allowing the seedlings to grow on until late May or June 
resulting in larger plants. Prior to outplanting, excessive top growth can again be trimmed by one- to two-thirds if plant height exceeds $30 \mathrm{~cm}$.

\section{VEGETATIVE PROPAGATION}

\section{Rhizome Harvest}

Rhizome sections (up to $20 \mathrm{~cm}$ ), with attached roots and leafy shoots, are harvested from natural sites in mid-June. We trim back all mature leaves by approximately two-thirds in the field, place rhizomes in plastic containers to retain moisture, and transport them under cool conditions to the greenhouse. Larger rhizome pieces $(10-15 \mathrm{~cm})$ are planted in pots of blonde peat (as described previously) whereas smaller sections are planted in Styroblock 1015A containers $(10 \mathrm{~cm}$ diameter with $2.5 \mathrm{~cm}$ diameter drain hole, $15 \mathrm{~cm}$ deep, and a volume of 1000 $\mathrm{ml}$ ). These divisions are between 3 and $10 \mathrm{~cm}$ long with at least one leafy shoot and some roots. Fertilize plants in the same manner as seedlings (saturated with a fertilizer solution of 117 ppm N, 77 ppm P, 165 ppm K).

\section{Rhizome Culture}

Cuttings grow quickly and produce large plants with numerous shoots and roots, and many produce elongate rhizomes up to $20 \mathrm{~cm}$ in length during the next $8 \mathrm{mo}$. The resulting large plants are further divided in late winter; we place $3-$ to $10-\mathrm{cm}$ rhizome pieces, with at least one small leafy shoot and a few roots, into 1015A Styroblock containers. Resulting plants are maintained in the greenhouse until June at which time they are sufficiently large and robust to be outplanted, removing excessive shoot growth by up to two-thirds as needed to achieve an approximate height of $30 \mathrm{~cm}$.

Larger plants remaining after cuttings are taken can be planted into large $\left(1.22 \mathrm{~m}^{2}\right)$ frames filled with the same media and maintained in the greenhouse as stooling material. Generally plants produced by rhizomes are fast growing and do not require overwintering prior to outplanting, but stock can be put into cold storage $\left(-3\right.$ to $\left.-4{ }^{\circ} \mathrm{C}\right)$ as described above for seedlings.

\section{OUTPLANTING}

We outplanted into various constructed wetlands in June along moist shorelines and into water depths up to $30 \mathrm{~cm}$. Survival is very good ( $>80 \%$ ), with some larger plants (generally those produced by rhizomes) flowering and producing seeds in the first year. By the second year, most plants are flowering.

\section{SUMMARY}

Ratroot is of particular importance to Aboriginal peoples of North America and as a food source for wildlife. As its habitat is impacted by oil sands operations, care is being taken to en- sure it remains part of boreal wetlands in future. Plants can be multiplied relatively quickly in the greenhouse by either division of rhizomes or from seeds. It is already included in the shorelines of several constructed wetlands and compensation lakes in northern Alberta.

\section{ACKNOWLEDGMENTS}

We thank our funders, operators in the Athabasca Oil Sands: Canadian Natural Resources Limited, Imperial Oil Limited, Shell Canada Limited, Suncor Energy Incorporated, Syncrude Canada Limited, and Total E\&P Canada Limited. Greenhouse work was carried out at Smoky Lake Forest Nursery, Smoky Lake, Alberta.

\section{REFERENCES}

Bush T. 2002. Sweet flag (Acorus calamus L.). URL: http://www.nrcs .usda.gov/Internet/FSE_PLANTMATERIALS/publications/mipmcfs30 81.pdf (accessed 27 Jan 2014). Baton Rouge (LA): USDA Natural Resources Conservation Service.

[ITIS] Integrated Taxonomic Information System. 2014. Acorus americanus. URL: http://itis.gov (accessed 15 Jul 2014). Washington (DC): National Museum of Natural History.

Marles R, larelle C, Monteleone L, Tays N, Burns D. 2000. Aboriginal plant use in Canada's northwest boreal forest. Natural Resources Canada and Canadian Forest Service. Vancouver (BC): University of British Columbia Press. 368 p.

Moss EH. 1983. Flora of Alberta. A manual of flowering plants, conifers, ferns, and fern allies found growing without cultivation in the province of Alberta, Canada. 2nd ed, revised by Packer JG. Toronto (ON): University of Toronto Press. 687 p.

Motley T. 1994. The ethnobotany of sweet flag, Acorus calamus (Araceae). Economic Botany 48(4):397-412.

\section{AUTHOR INFORMATION}

Ann Smreciu

Director

Wildrose.consulting@shaw.ca

Stephanie Wood

Steph_wood@live.com

Kimberly Gould

Kim.wildrose@shaw.ca

Wild Rose Consulting Inc

15109 - 77 Avenue

Edmonton, AB T5R $1 \mathrm{~L} 4$

Barry Wood (deceased)

Head Grower

Smoky Lake Forest Nursery

Smoky Lake, AB TOA 3C 

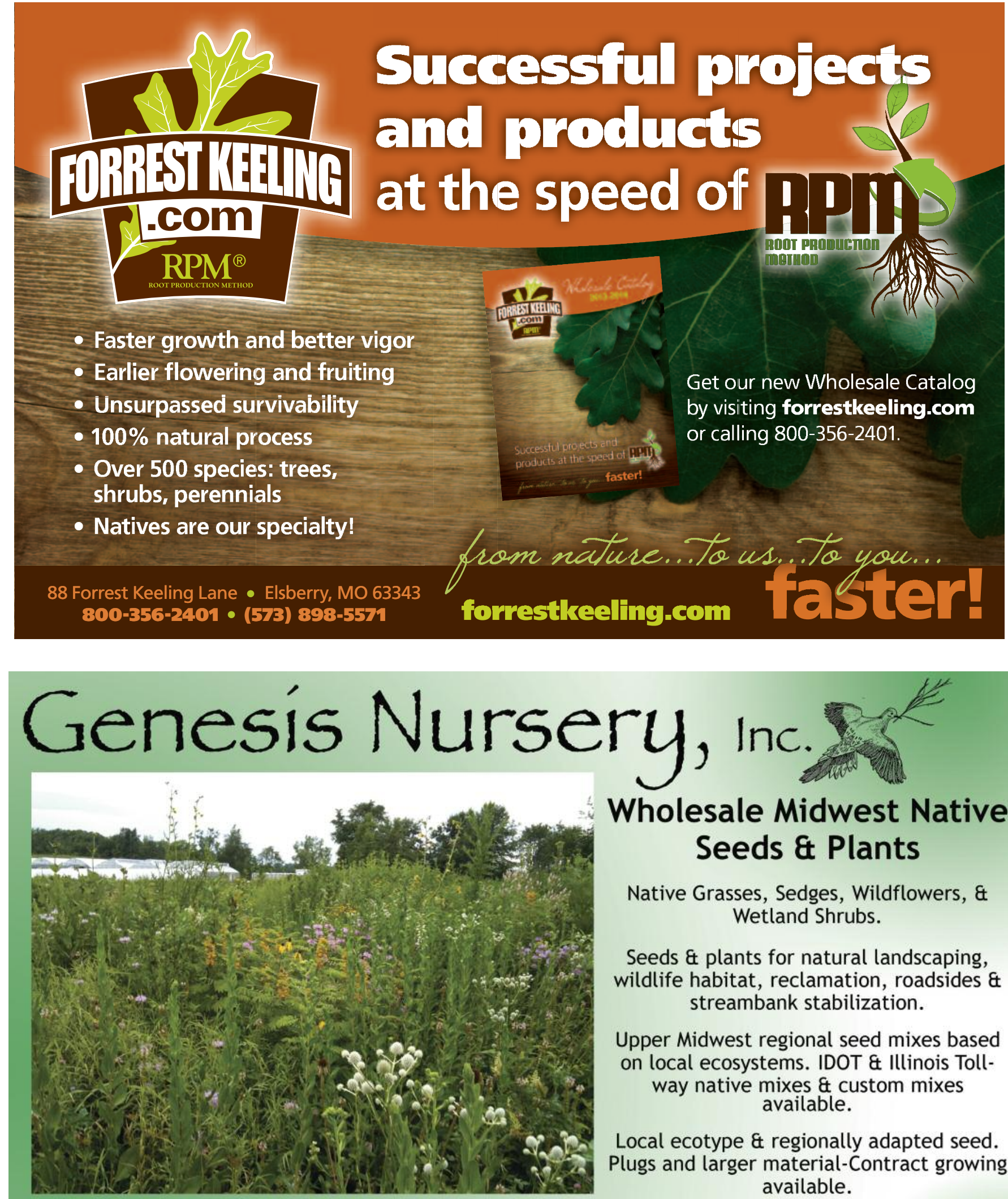

Send us your custom seed mix via fax or email. info@genesisnurseryinc.com

Toll Free: 877-817-5325 Fax: 815-438-2222

23200 Hurd Road Tampico, II 61283

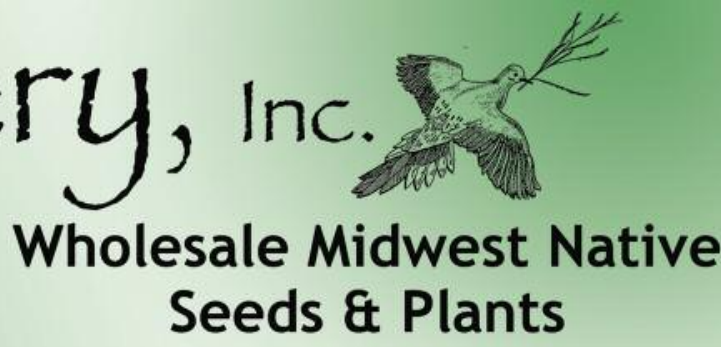

Native Grasses, Sedges, Wildflowers, \& Wetland Shrubs.

Seeds \& plants for natural landscaping, wildlife habitat, reclamation, roadsides \& streambank stabilization.

Upper Midwest regional seed mixes based on local ecosystems. IDOT \& Illinois Tollway native mixes \& custom mixes available.

Local ecotype \& regionally adapted seed. Plugs and larger material-Contract growing available.

Over 30 years experience in restoring Midwest landscapes.

wwW.genesisnurseryinc.com 